\title{
Profit Analysis of a System of Non-identical Units with Degradation and Replacement
}

\author{
Jitender Kumar \\ School of Mathematics and Computer \\ Applications, \\ Thapar University, Patiala (India)
}

\author{
M. S. Kadyan \\ Department of Statistics \& O.R., \\ Kurukshetra University, Kurukshetra (India)
}

\begin{abstract}
This paper presents the profit analysis of a system of two nonidentical units in which one unit is original which is initially operative and the other is duplicate kept in cold standby. The units may fail completely directly from normal mode. There is a single server who visits the system immediately when required. The original unit undergoes for repair upon failure while only replacement of the duplicate unit is made by similar new one. The original unit does not work as new after repair and so called degraded unit. The system is considered in up-state if any one of new/duplicate/degraded unit is operative. The server inspects the degraded unit at its failure to see the feasibility of repair. The failure time of the units are exponentially distributed whereas the distributions of inspection time, replacement time of the duplicate unit and repair time of the original/duplicate/degraded unit are taken as arbitrary with different probability density functions. Some reliability characteristics of the system model are evaluated using semi-Markov process and regenerative point technique. The numerical results for a particular case are also obtained to depict the behavior of Mean Time to System Failure (MTSF), availability and profit function graphically.
\end{abstract}

Key Words: System of Non-Identical Units, Inspection, Degradation, Replacement and Profit Analysis.

2000 Mathematics Subject Classification: Primary 90 B25 and Secondary $60 \mathrm{~K} 10$.

\section{INTRODUCTION}

In many industrial processes the provision of a standby unit is necessary for very high reliability. But it is not always possible to keep a high cost unit on standby. Therefore, to improve the reliability of a system, an ordinary unit (called duplicate) unit may be kept as spare which is capable of performing the same nominal system function but with different degree of reliability and desirability. An example, of this situation is a system comprised of an electrical device and a battery operated device. The battery device is switched on as and when the electrical device is failed.

The reliability models of standby systems have widely been studied by the engineers and scholars including Gopalan and Naidu (1984), Chung (1987) and Singh and Mishra (1994) under the assumptions that

i) The unit works as new after repair.

ii) Repair of the unit is always feasible.

Infect, these assumptions cannot be imposed always on every system. Because the working capacity and efficiency of a repaired unit depends on the skilled knowledge of the repair facility used. In case of being repaired by an ordinary server,

the chances of its failure may be high and thus such a unit may be considered as degraded. Malik et al. (2008) analyzed a system with inspection considering the concept of degradation of the unit after repair.

In view of the above facts and observations, we in this paper analyzed a system of non-identical units- one unit is original which is initially operative and other is its duplicate kept in cold standby. There is a single server who visits the server immediately when required. The original unit undergoes for repair upon failure while the duplicate unit is replaced by similar new one. The original unit does not work as new after repair and so called degraded unit. The system is considered in up-state if any one of new/duplicate/degraded unit is operative. The server inspects the degraded unit at its failure to see the feasibility of repair. If repair of the degraded unit is not feasible, it is replaced by new one similar to the original unit in negligible time. The failure time of the units are exponentially distributed whereas the distributions of inspection time, replacement time of the duplicate unit and repair time of the original/duplicate/degraded unit are taken as arbitrary with different probability density functions. The random variables are mutually independent and uncorrelated. The expressions for some reliability characteristics such as mean sojourn times, Mean Time to System Failure, availability, busy period of the server, expected number of visits by the server and profit function are derived using semiMarkov process and regenerative point technique. The numerical results considering a particular case are also obtained to depict the graphically behavior of Mean Time to System Failure (MTSF), availability and profit of the system model.

\section{NOTATIONS}

$\mathrm{E}$

No

DUo

Do

Ncs /DUcs/Dcs

$\mathrm{p} / \mathrm{q}$

$\lambda / \lambda_{1} / \lambda_{2}$

$\mathrm{g}(\mathrm{t}) / \mathrm{G}(\mathrm{t})$, $\mathrm{g}_{1}(\mathrm{t}) / \mathrm{G}_{1}(\mathrm{t})$
:Set of regenerative states

:The unit is new and operative

:The unit is duplicate and operative

:The unit is degraded and operative

:The new/duplicate/degraded unit in cold standby

:Probability that repair of degraded unit is feasible/not feasible

:Constant failure rate of new/duplicate /degraded unit

:pdf/cdf of repair time for new/degraded unit 
$\mathrm{w}(\mathrm{t}) / \mathrm{W}(\mathrm{t})$

$h(t) / H(t)$

$\mathrm{N}_{\text {fur }} / \mathrm{N}_{\mathrm{FUR}} / \mathrm{N}_{\mathrm{fwr}}$

$\mathrm{DU}_{\text {fure }} / \mathrm{DU}_{\mathrm{FUR}}$

$\mathrm{DU}_{\mathrm{fwre}} / \mathrm{DU}_{\mathrm{FWRe}}$

$\mathrm{D}_{\text {fur }} / \mathrm{D}_{\mathrm{FUR}}$

$\mathrm{D}_{\text {fui }} / \mathrm{D}_{\text {fwi }} / \mathrm{D}_{\mathrm{FUI}}$

$\mathrm{q}_{\mathrm{ij}}(\mathrm{t}), \mathrm{Q}_{\mathrm{ij}}(\mathrm{t})$

$\mathrm{q}_{\mathrm{ij} . k r}(\mathrm{t}), \mathrm{Q}_{\mathrm{ij} . k \mathrm{r}}(\mathrm{t})$

$\mathrm{M}_{\mathrm{i}}(\mathrm{t})$

$\mathrm{W}_{\mathrm{i}}(\mathrm{t})$

$m_{i j}$

(®/C

$\sim *$

'(dash)

The following are the possible transition states of the system model

$$
\begin{aligned}
& S_{0}=(\text { No, }, \text { DUcs }) \\
& S_{2}=\left(D_{\text {fwre }}, N_{\text {FUR }}\right) \\
& S_{4}=\left(\text { Do }, D_{\text {fure }}\right) \\
& S_{6}=(\text { Do }, \text { DUcs }) \\
& S_{8}=\left(\text { DUo }, D_{\text {fur }}\right)
\end{aligned}
$$$$
S_{1}=\left(D U o, N_{\text {fur }}\right)
$$$$
\mathrm{S}_{3}=(\mathrm{DU}, \mathrm{Dcs})
$$

:pdf/cdf of replacement time of the duplicate unit

:pdf/cdf of inspection time of the degraded unit

:New unit is failed and under repair/under continuous repair from previous state/waiting for repair.

-Duplicate unit is failed and under/ replacement/under continuous replacement from previous state/ waiting for replacement/continuously waiting for replacement from previous state.

:Degraded unit is failed and under repair/under repair continuously from previous state.

:Degraded unit is failed and under inspection/waiting

inspection/under inspection continuously from the previous state.

:pdf and cdf of first passage time from regenerative state $i$ to a regenerative state $j$ or to a failed state $j$ without visiting any other regenerative state in $(0, t]$.

pdf and cdf of first passage time from regenerative state $i$ to a regenerative state $j$ or to a failed state $j$ visiting state $\mathrm{k}, \mathrm{r}$ once in $(0, \mathrm{t}]$.

:Probability of system up initially in state $\mathrm{S}_{\mathrm{i}} \in \mathrm{E}$ is up at time $t$ without visiting to any other regenerative sate

:Probability of server is busy in the state $\mathrm{S}_{\mathrm{i}}$ up to time $t$ without making any transition to any other regenerative state or returning to the same via one or more nonregenerative states.

:Contribution to mean sojourn time in state $S_{i} \in E$ and non regenerative state if occurs before transition to $S_{j} \in E$. Laplace convolution

:Symbols for Laplace Stieltjes Transform (LST)/Laplace Transform (LT) 


$$
\begin{array}{ll}
\mathrm{m}_{01}=\mu_{0} & \mathrm{~m}_{12}+\mathrm{m}_{13}=\mu_{1} \\
\mathrm{~m}_{13}+\mathrm{m}_{14.2}=\mu_{1}^{1} \text { (say) } & \mathrm{m}_{34}=\mu_{3} \\
\mathrm{~m}_{45}+\mathrm{m}_{46}=\mu_{4} & \mathrm{~m}_{46}+\mathrm{m}_{4,7.5}=\mu_{4}^{1} \text { (say) } \\
\mathrm{m}_{67}=\mu_{6} & \mathrm{~m}_{7,8}+\mathrm{m}_{7,10}+\mathrm{m}_{7,9}=\mu_{7} \\
\mathrm{~m}_{7,8}+\mathrm{m}_{7,10}+\mathrm{m}_{7,11.9}+\mathrm{m}_{7,49,13}=\mu_{7}^{1} \text { (say) } \\
\mathrm{m}_{83}+\mathrm{m}_{8,12}=\mu_{8} & \mathrm{~m}_{83}+\mathrm{m}_{8,4.12}=\mu_{8}^{1} \text { (say) } \\
\mathrm{m}_{10,11}=\mu_{11} & \mathrm{~m}_{11,14}+\mathrm{m}_{11,0}=\mu_{11}
\end{array}
$$$$
\mathrm{m}_{11,0}+\mathrm{m}_{11,1.14}=\mu_{11}^{1} \text { (say) }
$$

\section{MEAN TIME TO SYSTEM FAILURE}

Let $\phi_{\mathrm{i}}(\mathrm{t})$ be the cdf of the first passage time from regenerative state $i$ to a failed state. Regarding the failed state as absorbing state, we have the following recursive relations for $\phi_{\mathrm{i}}(\mathrm{t})$ :

$$
\phi_{\mathrm{i}}(\mathrm{t})=\sum_{\mathrm{j}} \mathrm{Q}_{\mathrm{i}, \mathrm{j}}(\mathrm{t}) \circledast \phi_{\mathrm{j}}(\mathrm{t})+\sum_{\mathrm{k}} \mathrm{Q}_{\mathrm{i}, \mathrm{k}}(\mathrm{t})
$$

where $j$ is an operative regenerative state to which the given regenerative state $i$ can transit and $k$ is a failed state to which the state $i$ can transit directly.

Taking L.S.T. of relations (6) and solving for $\tilde{\phi}_{0}(\mathrm{~s})$.

Using this, we have

$$
\mathrm{R}^{*}(\mathrm{~s})=\left(1-\tilde{\phi}_{0}(\mathrm{~s})\right) / \mathrm{s}
$$

The reliability $\mathrm{R}(\mathrm{t})$ can be obtained by taking Laplace inverse transform of (7)

The mean time to system failure can be given by

$$
\operatorname{MTSF}\left(T_{1}\right)=\operatorname{limR}_{s \rightarrow 0}^{*}(s)=\frac{N_{11}}{D_{11}}
$$

where

$$
\begin{aligned}
\mathrm{N}_{11} & =\mathrm{p}_{13}\left[\mu_{0}+\mu_{3}+\mu_{4}+\mathrm{p}_{46}\left\{\left(\mu_{6}+\mu_{7}\right)+\mathrm{p}_{78} \mu_{8}+\mathrm{p}_{7,10}\left(\mu_{10}+\mu_{11}\right)\right\}\right] \\
& -\mathrm{p}_{78} \mathrm{p}_{83} \mathrm{p}_{46}\left(\mu_{0}+\mu_{1}\right)
\end{aligned}
$$

and

$$
\mathrm{D}_{11}=1-\mathrm{p}_{7,10} \mathrm{p}_{46} \mathrm{p}_{13} \mathrm{p}_{11,0}-\mathrm{p}_{78} \mathrm{p}_{46} \mathrm{p}_{83}
$$

\section{AVAILABILITY ANALYSIS}

Let $\mathrm{A}_{\mathrm{i}}(\mathrm{t})$ be the probability that the system is in up state at instant $t$ given that the system entered regenerative state $i$ at $t=0$. The recursive relations for $\mathrm{A}_{\mathrm{i}}(\mathrm{t})$ are given by :

$$
A_{i}(t)=M_{i}(t)+\sum_{j} q_{i, j}^{(n)}(t) \odot A_{j}(t)
$$

where $j$ is any successive regenerative state to which the regenerative state $i$ can transit through $\mathrm{n} \geq 1$ (natural number) transitions.

We have,

$$
\begin{array}{lr}
M_{0}(t)=e^{-\lambda t} & M_{1}(t)=e^{-\lambda_{1} t} \bar{G}(t) \\
M_{3}(t)=e^{-\lambda_{1} t}=M_{10}(t) & M_{4}(t)=e^{-\lambda_{2} t} \bar{W}(t) \\
M_{6}(t)=e^{-\lambda_{2} t} & M_{7}(t)=e^{-\lambda_{1} t} \bar{H}(t) \\
M_{8}(t)=e^{-\lambda_{1} t} \bar{G}_{1}(t) & M_{11}(t)=e^{-\lambda t} \bar{W}(t),
\end{array}
$$

Taking LT of relations (9) and solving for $\mathrm{A}_{0} *(\mathrm{~s})$.

The steady-state availability of the system can be given by

$$
A_{0}(\infty)=\lim _{s \rightarrow 0} s A_{0}^{*}(s)=\frac{N_{12}}{D_{12}}
$$

where

$$
\begin{aligned}
\mathrm{N}_{12}= & \left(\mathrm{p}_{7,10}+\mathrm{p}_{7,11.9}\right)\left(\mu_{0} \mathrm{p}_{11,0}+\mu_{1}+\mu_{11}\right)+\left[\mu_{4}+\mathrm{p}_{46} \mu_{6}+\mu_{7}+\mathrm{p}_{7,8} \mu_{8}\right. \\
& \left.+\mathrm{p}_{7,10} \mu_{10}\right]+\mu_{3}\left[\mathrm{p}_{13}\left(\mathrm{p}_{7,10}+\mathrm{p}_{7,11.9}+\mathrm{p}_{78} \mathrm{p}_{83}\right]\right. \\
\mathrm{D}_{12}= & \left(\mathrm{p}_{7,10}+\mathrm{p}_{7,11.9}\right)\left[\mu_{0} \mathrm{p}_{11,0}+\mu_{3} \mathrm{p}_{13}+\mu_{1}^{1}+\mu_{11}^{1}\right]+\mathrm{p}_{78}\left(\mu_{8}^{1}+\mathrm{p}_{83} \mu_{3}\right) \\
& +\mu_{4}^{1}+\mathrm{p}_{46} \mu_{6}+\mu_{7}^{1}+\mathrm{p}_{7,10} \mu_{10}
\end{aligned}
$$

\section{BUSY PERIOD ANALYSIS FOR SERVER}

Let $\mathrm{B}_{\mathrm{i}}(\mathrm{t})$ be the probability that the server is busy at an instant $t$ given that the system entered regenerative state $i$ at $t=0$. The following are the recursive relations for $\mathrm{B}_{\mathrm{i}}(\mathrm{t})$

$$
\mathrm{B}_{\mathrm{i}}(\mathrm{t})=\mathrm{W}_{\mathrm{i}}(\mathrm{t})+\sum_{j} \mathrm{q}_{\mathrm{i}, \mathrm{j}}^{(\mathrm{n})}(\mathrm{t}) \odot \mathrm{B}_{\mathrm{j}}(\mathrm{t})
$$

where $j$ is a subsequent regenerative state to which state $i$ transits through $n \geq 1$ (natural number) transitions.

We have,

$$
\begin{aligned}
\mathrm{W}_{1}(\mathrm{t})= & {\left[\mathrm{e}^{-\lambda_{1} \mathrm{t}}+\left(\lambda_{1} \mathrm{e}^{-\lambda_{1} \mathrm{t}} \mathrm{C}\right)\right] \overline{\mathrm{G}}(\mathrm{t}) } \\
\mathrm{W}_{4}(\mathrm{t})= & {\left[\mathrm{e}^{-\lambda_{2} \mathrm{t}}+\left(\lambda_{2} \mathrm{e}^{-\lambda_{2} \mathrm{t}} \odot 1\right)\right] \overline{\mathrm{W}}(\mathrm{t}) } \\
\mathrm{W}_{7}(\mathrm{t})= & \mathrm{e}^{-\lambda_{1} \mathrm{t}} \overline{\mathrm{H}}(\mathrm{t})+\left[\left(\lambda_{1} \mathrm{e}^{-\lambda_{1} \mathrm{t}} \odot 1\right)\right] \overline{\mathrm{H}}(\mathrm{t}) \\
& +\left(\lambda_{1} \mathrm{e}^{-\lambda_{1} \mathrm{t}} \odot \mathrm{ph}(\mathrm{t})(1) \overline{\mathrm{G}}_{1}(\mathrm{t})\right. \\
\mathrm{W}_{8}(\mathrm{t})= & \mathrm{e}^{-\lambda_{1} \mathrm{t}} \overline{\mathrm{G}}_{1}(\mathrm{t})+\left[\left(\lambda_{1} \mathrm{e}^{-\lambda_{1} \mathrm{t}} \odot 1\right)\right] \overline{\mathrm{G}}_{1}(\mathrm{t}) \\
\mathrm{W}_{11}(\mathrm{t})= & {\left[\mathrm{e}^{-\lambda \mathrm{t}}+\left(\lambda_{1} \mathrm{e}^{-\lambda \mathrm{t}} \odot 1\right)\right] \overline{\mathrm{W}}(\mathrm{t}) . }
\end{aligned}
$$

Taking LT of relations (12) and solving for $\mathrm{B}_{0} *(\mathrm{~s})$ and using this, we can obtain the fraction of time for which the repairman is busy in steady state

$$
\begin{aligned}
& \mathrm{B}_{0}=\underset{\mathrm{s} \rightarrow 0}{\operatorname{Lims}} \mathrm{B}_{0}^{*}(\mathrm{~s})=\frac{\mathrm{N}_{13}}{\mathrm{D}_{12}} \\
\mathrm{~N}_{13}= & \left(\mathrm{p}_{7,10}+\mathrm{p}_{7,11.9}\right)\left(\mathrm{W}_{1}^{*}(0)+\mathrm{W}_{11}^{*}(0)\right)+\mathrm{W}_{4}^{*}(0)+\mathrm{W}_{7}^{*}(0) \\
& +\mathrm{p}_{78} \mathrm{~W}_{8}^{*}(0)
\end{aligned}
$$

and $\mathrm{D}_{12}$ is already mentioned.

\section{EXPECTED NUMBER OF VISITS BY SERVER}

Let $\mathrm{N}_{\mathrm{i}}(\mathrm{t})$ be the expected number of visits by the server in $(0, t]$ given that the system entered the regenerative state $i$ at $t=0$. We have the following recursive relations for $\mathrm{N}_{\mathrm{i}}(\mathrm{t})$ :

$$
\mathrm{N}_{\mathrm{i}}(\mathrm{t})=\sum_{\mathrm{j}} \mathrm{Q}_{\mathrm{i}, \mathrm{j}}(\mathrm{t}) \mathbb{R}\left[\delta_{\mathrm{j}}+\mathrm{N}_{\mathrm{j}}(\mathrm{t})\right]
$$


where $\mathrm{j}$ is any regenerative state to which the given regenerative state $i$ transits and $\delta_{\mathrm{i}}=1$, if $j$ is the regenerative state where the server does job afresh otherwise $\delta_{i}=0$.

Taking LST of relations (15) and solving for $\tilde{\mathrm{N}}_{0}(\mathrm{~s})$.

The expected number of visits per unit time are given by

$$
\mathrm{N}_{0}=\lim _{\mathrm{s} \rightarrow 0} \mathrm{~s} \tilde{\mathrm{N}}_{0}(\mathrm{~s})=\frac{\mathrm{N}_{14}}{\mathrm{D}_{12}}
$$

where $\mathrm{N}_{14}=\left(\mathrm{p}_{7,10}+\mathrm{p}_{7,11.9}\right)\left(\mathrm{p}_{11,0}+\mathrm{p}_{13}\right)+\mathrm{p}_{46}+\mathrm{p}_{83} \mathrm{p}_{7,8}+\mathrm{p}_{7,10}$ and $\mathrm{D}_{12}$ is already specified.

\section{PROFIT ANALYSIS}

Profit incurred to the system model in steady state is given by

$$
\mathrm{P}_{1}=\mathrm{K}_{1} \mathrm{~A}_{0}-\mathrm{K}_{2} \mathrm{~B}_{0}-\mathrm{K}_{3} \mathrm{~N}_{0}
$$

Where $\quad \mathrm{K}_{1}=$ Revenue per unit up time of the system

$\mathrm{K}_{2}=$ Cost per unit time for which server is busy

$\mathrm{K}_{3}=$ Cost per visit by the server

\section{PARTICULAR CASE}

Let us take $g(t)=\theta \mathrm{e}^{-\theta t}, \mathrm{~g}_{1}(\mathrm{t})=\theta_{1} \mathrm{e}^{-\theta_{1} \mathrm{t}}, \quad \mathrm{h}(\mathrm{t})=\alpha \mathrm{e}^{-\alpha \mathrm{t}}$ and $\mathrm{w}(\mathrm{t})=\beta \mathrm{e}^{-\beta \mathrm{t}}$.

By using the non-zero elements $\mathrm{p}_{\mathrm{i} i}$, we get the following results:

$\operatorname{MTSF}\left(\mathrm{T}_{1}\right)=\mathrm{N}_{11} / \mathrm{D}_{11}, \quad$ Availability $\left(\mathrm{A}_{0}\right)=\mathrm{N}_{12} / \mathrm{D}_{12}$

Busy Period $\left(B_{0}\right)=N_{13} / D_{12}$, Expected no. of visits $\left(N_{0}\right)=N_{14} / D_{12}$ where

$$
\begin{aligned}
\mathrm{D}_{11}= & \lambda \lambda_{1} \lambda_{2}\left[\left(\theta+\lambda_{1}\right)\left(\alpha+\lambda_{1}\right)\left(\lambda_{1}+\theta_{1}\right)\left(\beta+\lambda_{2}\right)(\beta+\lambda)\right. \\
& \left.-\mathrm{q} \theta \alpha \beta^{2}\left(\lambda_{1}+\theta_{1}\right)-\mathrm{p} \theta_{1} \alpha \beta\left(\lambda_{1}+\theta\right)(\beta+\lambda)\right] \\
\mathrm{N}_{11}= & \theta\left[\left\{\left(\lambda_{1}+\lambda\right)\left(\beta+\lambda_{2}\right)+\lambda_{1}\right\} \lambda_{2}\left(\alpha+\lambda_{1}\right)\left(\lambda_{1}+\theta_{1}\right)(\beta+\lambda)\right. \\
& +\left(\theta+\lambda_{1}\right) \lambda \beta\left\{\lambda_{1}(\beta+\lambda)\left\{\left(\lambda_{1}+\alpha+\lambda_{2}\right)\left(\lambda_{1}+\theta_{1}\right)+\mathrm{p} \alpha \lambda_{2}\right\}\right. \\
& \left.\left.+\lambda_{2} \alpha \mathrm{q}\left(\lambda_{1}+\theta_{1}\right)\left(\beta+\lambda+\lambda_{1}\right)\right\}\right] \\
& -\lambda_{1} \theta_{1} \lambda_{2} \alpha \mathrm{p} \beta\left(\theta+\lambda_{1}+\lambda\right)(\beta+\lambda) \\
\mathrm{D}_{12}= & \mathrm{q} \lambda_{2} \theta_{1}\left(\alpha+\lambda_{1}\right)\left(\lambda_{1}+\theta_{1}\right)\left(\beta+\lambda_{2}\right)\left[\lambda _ { 1 } ( \theta + \lambda _ { 1 } ) \left\{\beta^{2} \theta\right.\right. \\
& \left.+(\beta+\theta)(\beta+\lambda) \lambda\}+\lambda \beta \theta^{2}(\beta+\lambda)\right]+\mathrm{p} \alpha \lambda \theta \lambda_{2} \beta\left[\lambda_{1}\left(\lambda_{1}+\theta_{1}\right)\right. \\
& \left.+\theta_{1}^{2}\right]\left(\theta+\lambda_{1}\right)\left(\beta+\lambda_{2}\right)(\beta+\lambda)+\lambda \theta_{1} \theta\left(\theta+\lambda_{1}\right)\left(\lambda_{1}+\theta_{1}\right) \\
& (\beta+\lambda)\left[\lambda_{2}\left(\beta+\lambda_{2}\right)\left\{\lambda_{1}(1+\mathrm{A} \beta)\left(\alpha+\lambda_{1}\right)+\mathrm{q} \beta \alpha\right\}\right. \\
& \left.+\beta^{2} \lambda_{1}\left(\alpha+\lambda_{1}\right)\right] \\
\mathrm{N}_{12}= & \beta \theta \theta_{1}\left[\mathrm{q} \lambda_{1} \lambda\left(\alpha+\lambda_{1}\right)\left(\lambda_{1}+\theta_{1}\right)\left(\beta+\lambda_{2}\right)(\beta+\lambda)\left(\lambda_{1}+\theta+\lambda\right)\right. \\
& +\lambda\left(\theta+\lambda_{1}\right)(\beta+\lambda)\left[\lambda_{1}\left(\alpha+\lambda_{1}\right)\left(\lambda_{1}+\theta_{1}\right)+\left\{\lambda_{1}\left(\mathrm{p} \alpha+\lambda_{1}+\theta_{1}\right)\right.\right. \\
& \left.\left.+\mathrm{q} \alpha\left(\theta_{1}+\lambda_{1}\right)\right\} \lambda_{2}\right]+\lambda \lambda_{2}\left(\beta+\lambda_{2}\right)(\beta+\lambda)\left[\mathrm{q} \theta\left(\alpha+\lambda_{1}\right)\left(\lambda_{1}+\theta_{1}\right)\right. \\
& \left.\left.+\mathrm{p} \alpha \theta_{1}\left(\theta+\lambda_{1}\right)\right]\right] \\
\mathrm{N}_{13}= & \lambda \lambda_{1} \lambda_{2}\left(\theta+\lambda_{1}\right)\left(\lambda_{1}+\theta_{1}\right)\left(\beta+\lambda_{2}\right)(\beta+\lambda)\left[\theta_{1}\left(\alpha+\lambda_{1}\right)\right. \\
& {[\mathrm{q}(\theta+\beta)+\theta(1+\beta \mathrm{B})]+\mathrm{p} \theta \alpha \beta] }
\end{aligned}
$$

$$
\begin{aligned}
\mathrm{N}_{14} & =\lambda \lambda_{1} \lambda_{2} \theta \theta_{1} \beta\left(\alpha+\lambda_{1}\right)\left(\lambda_{1}+\theta_{1}\right)\left(\beta+\lambda_{2}\right)+\left[\beta\left(\theta+\lambda_{1}\right)\right. \\
& +\theta(\beta+\lambda)]+\operatorname{p} \alpha \theta_{1}\left(\theta+\lambda_{1}\right)\left(\beta+\lambda_{2}\right)(\beta+\lambda)+\left(\left(\alpha+\lambda_{1}\right) \beta\right. \\
& \left.+\mathrm{q} \alpha\left(\lambda_{2}+\beta\right)\right)\left(\theta+\lambda_{1}\right)\left(\lambda_{1}+\theta_{1}\right)(\beta+\lambda) \\
\mathrm{A}= & {\left[\left[\mathrm{q}\left(\alpha+\lambda_{1}\right)^{2}+\alpha^{2} \mathrm{p}\right] \alpha \theta_{1}+\mathrm{q} \alpha\left[\left(\theta_{1}+\alpha\right)\left(\alpha+\lambda_{1}\right)^{2}\right.\right.} \\
& \left.\left.-\alpha^{2}\left(\alpha+\theta_{1}+\lambda_{1}\right)\right]\right] /\left[\left(\theta_{1} \alpha^{2}\left(\alpha+\lambda_{1}\right)^{2}\right]\right. \\
\mathrm{B}= & {\left[\theta_{1}\left(\alpha+\theta_{1}\right)\left(\theta_{1}+\lambda_{1}\right)+\alpha^{2} \mathrm{p} \lambda_{1}\right] /\left[\theta_{1} \alpha\left(\alpha+\theta_{1}\right)\left(\theta_{1}+\lambda_{1}\right)\right] . }
\end{aligned}
$$

\section{CONCLUSION}

From fig.2, fig. 3 and fig.4, it is concluded that mean time to system failure (MTSF), availability and profit function decrease with the increase of failure rates $\lambda$ and $\lambda_{2}$ for fixed values of other parameters including $\mathrm{p}=.7$ and $\mathrm{q}=.3$. However, their values increase if repair rate $(\theta)$ and replacement rate $(\beta)$ of duplicate unit increase. It is interesting to note that the system becomes more profitable by interchanging the values of $\mathrm{p}$ and $\mathrm{q}$.

Hence, on the basis of the results obtained for a particular case, it is suggested that replacement of the failed degraded unit by original unit should be preferred over the repair to increase of a system of non-identical units.

\section{REFERENCES}

[1] Murari, K. and Goyal, V. 1984. Comparison of two-unit cold standby reliability models with three types of repair facilities. Microelectron. Reliab. 24(1), 35-49.

[2] Gopalan, M. N. and Naidu, R. S. 1982. Cost- benefit analysis of a one-server two-unit cold standby system subject to inspection. Microelectron. Reliab. 22(4), 699-705.

[3] Mokaddis, G. S., Labib, S. W. and Ahmed, A.M. 1997. Analysis of a two-unit warm standby system subject to degradation, Microelectron. Reliab, 37(4), 641-647.

[4] Malik, S. C., Chand, P. and Singh, J. 2008. Stochastic analysis of an operating system with two types of inspection subject to degradation. Journal of Applied Probability and Statistics (USA). 3(2), 227-241.

[5] Singh, S. K. and Mishra, A. K. 1994. Profit evaluation of a two-unit cold standby redundant system with two operative modes. Microelectron. Reliab. 34(4), 747-750.

[6] Chung, W. K. 1987. Reliability analysis of a repairable parallel system with standby involving human error and common cause failures. Microelectron. Reliab. 27(2), 269-271.

[7] Kumar, J. 2011. Cost-Benefit Analysis of a Redundant System with Inspection and priority subject to degradation. International Journal of Computer Science Issues. 8(6), 314-321.

[8] Kumar, J., Kadyan M. S. and Malik, S. C. 2010. CostBenefit Analysis of a two-unit parallel system subject to degradation after repair. Applied Mathematical Sciences. 4(5), 2749-2758.

[9] Malik, S.C., Bhardwaj, R.K. and Grewal, A.S. 2010. Probabilistic analysis of a system of two non-identical parallel units with priority to repair subject to inspection Journal of Reliability and Statistical Studies, 3(1), 1-11 
[10] Khaled, M. El-Said. and Mohamed, S. El-Sherbeny. 2010.Stochastic analysis of a two-unit cold standby system with two-stage repair and waiting time, Sankhya:The Indian Journal of Statistics,72-B (1), $1-10$.
[11] Cox, D. R. 1962 Renewal theory, Chapman \& Hall.

[12] Medhi, J. 1982 Stochastic Processes, Wiley Eastern Limited, India.

\section{State Transition Diagram (Fig.1)}

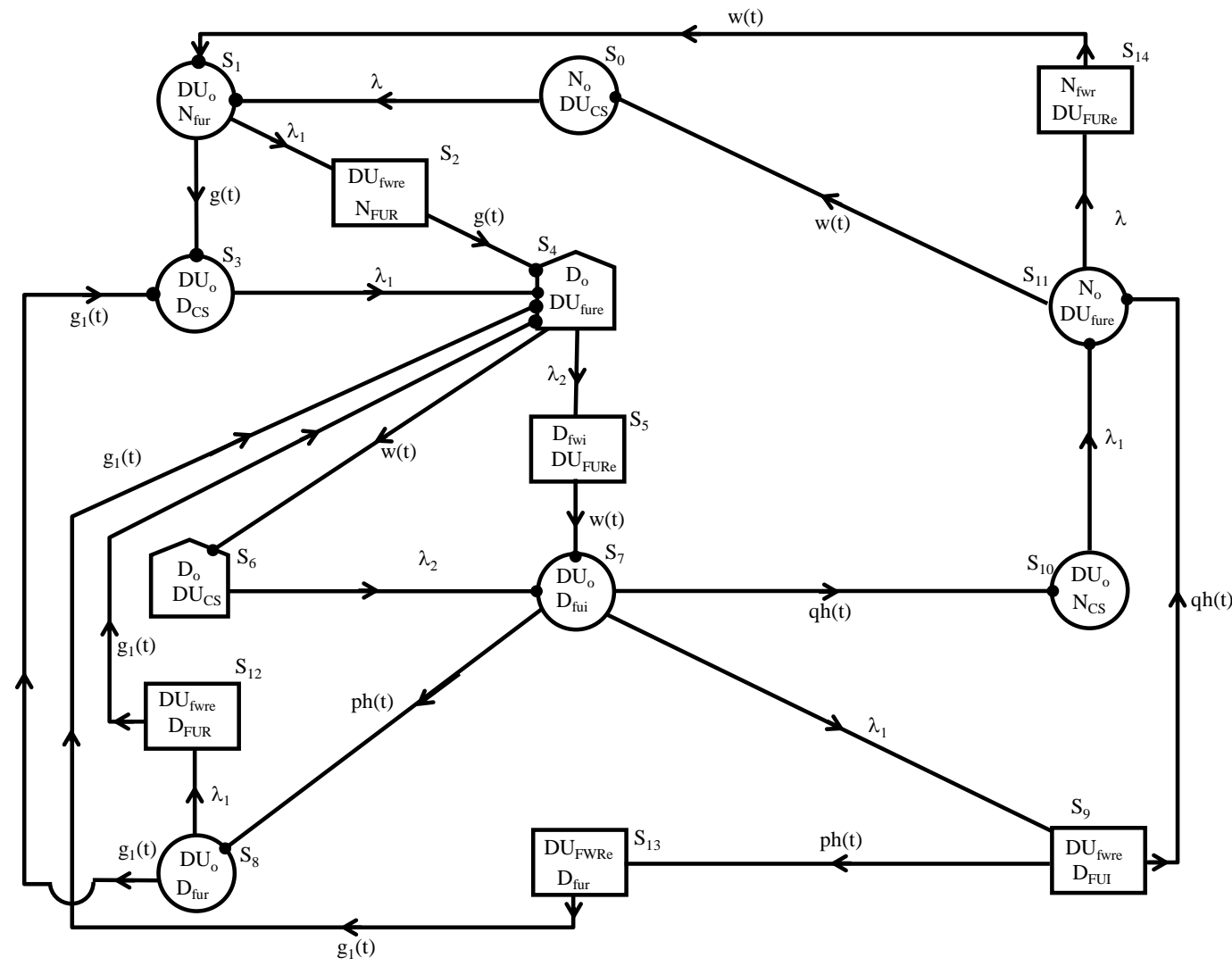

$\begin{array}{ll}\text { : Transition point } & \square \text { : Degraded-State } \\ \text { : Up-State } & \square \text { : Failed-State }\end{array}$ 

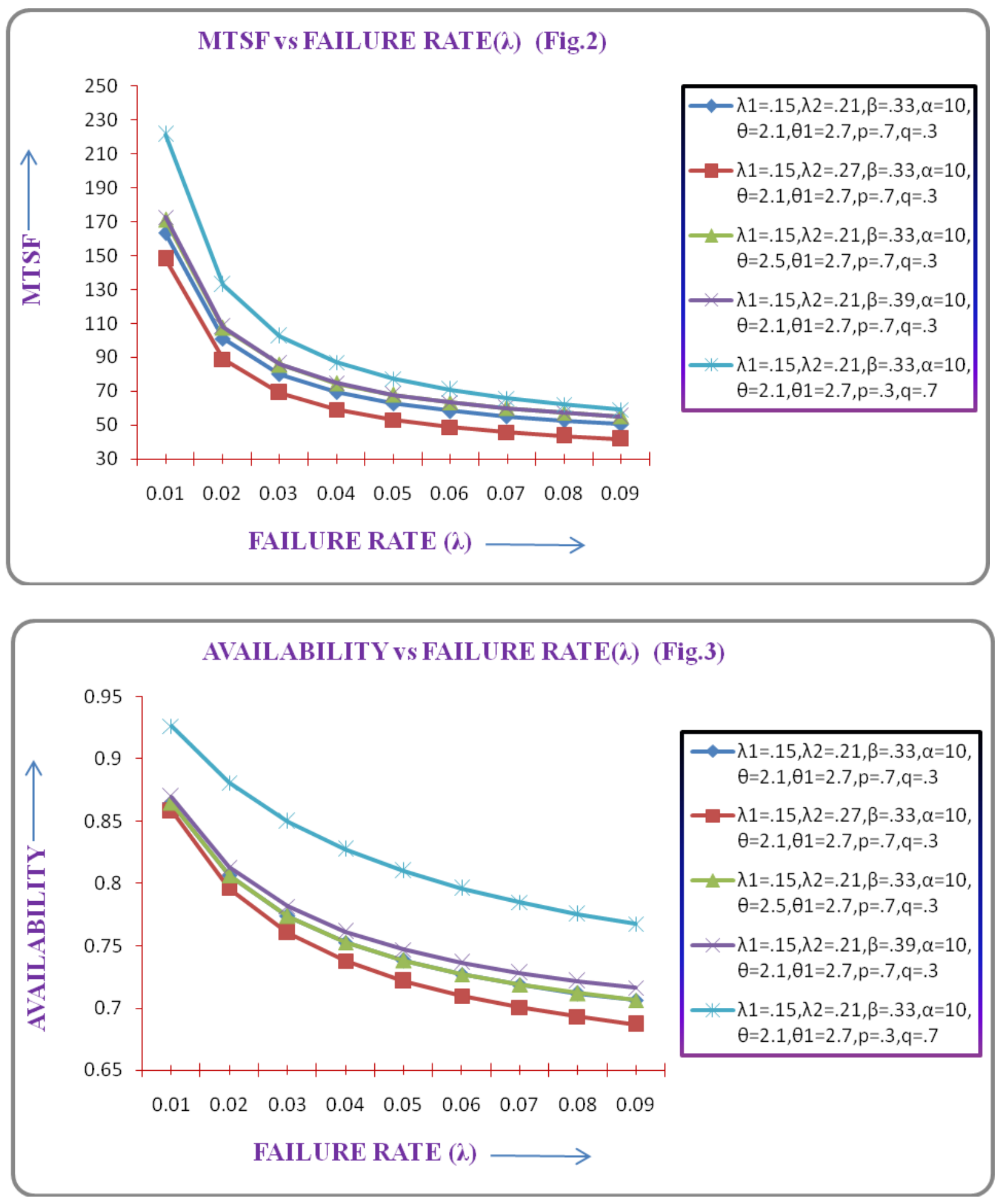


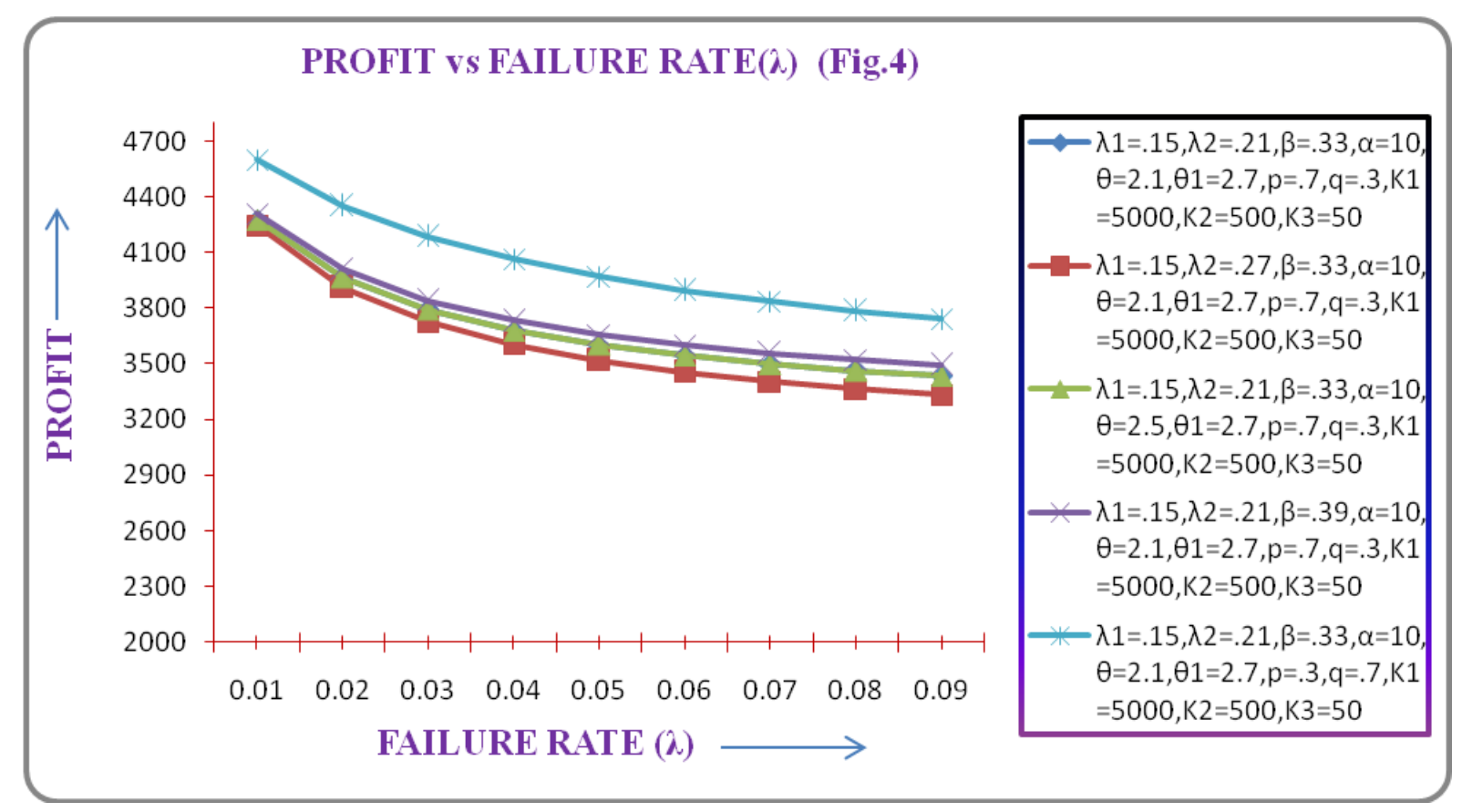

